\title{
Escaleta: Cine y Psicoanálisis
}

\author{
Francisco Cabanillas"
}

USAL, Argentina

Recibido: 30 de mayo de 2021; aprobado 15 de junio de 2021

\section{Resumen}

El presente trabajo pretende abordar, a través de un sucinto recorrido por diversas manifestaciones artísticas e ideas del pensamiento filosófico, los conceptos de lo apolíneo y lo dionisíaco. Estos dos conceptos -reflejados en la tradición científica y el arte, respectivamente- resumen dos acercamientos opuestos para tratar con lo Real, ya sea a través de la Razón o de la experiencia estética. Se argumenta, además, que -por ejemplo- el cine y el psicoanálisis representan una articulación de lo apolíneo y lo dionisíaco. En cualquier caso, se discuten las relaciones con la verdad tanto de la experiencia analítica como de la experiencia artística y se plantea que ambas se dirigen a mostrar lo Real, es decir aquella verdad que no puede ser descrita en palabras.

Palabras Clave: Apolíneo | Dionisíaco | Real | Arte | Verdad

\begin{abstract}
The present work aims to address, through a brief tour of various artistic manifestations and ideas of philosophical thought, the concepts of the Apollonian and the Dionysian. These two concepts -reflected in the scientific tradition and art, respectively-summarize two opposing approaches to dealing with the Real, either through Reason or through aesthetic experience. It is also argued that -for instance- cinema and psychoanalysis represent an articulation of the Apollonian and the Dionysian. In any case, the relationships with the truth of both the analytical experience and the artistic experience are discussed and it is proposed that both are directed to show the Real, that is, that truth that cannot be described in words.
\end{abstract}

Keywords: Apollonian | Dionysian | Real | Art | Truth

\section{1 - OSCURIDAD.}

\section{Sobre impresión: Cabalgando entre Apolo y}

\section{Dionisios...}

\section{Luego: Atenas s. IV. A.C.}

Sonido de flautas, tambores, cascabeles, voces de multitud cantando....

\section{ABRE NEGRO:}

\section{2 a - EXT - VALLE FUERA DE ATENAS. - DIA.}

B/N. Formato: 4:3.

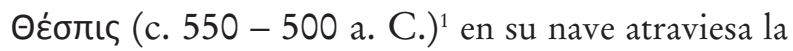
marea de espectadores presentes en las Dionisíacas. Con

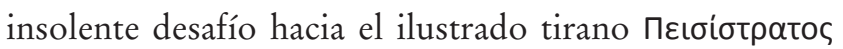
(c. 607-527 a. C.) $)^{2}$ desembarcó en medio de los sátiros para plantar bandera. “...Platón decía que Grecia no era una democracia sino una teatrocracia” (Chancerel, 1940/1963, p. 9). Su porta estandarte: el héroe; entonces

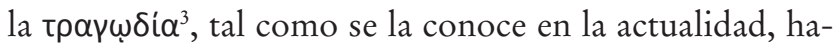
bía invadido Grecia. Las representaciones rituales histórico-miméticos se vieron forzadas a exiliarse hacia otros espacios.
La tragedia, prende fuerte sobre el terreno fértil del $\delta ı \theta \dot{p} \alpha \mu \beta \varsigma^{4}$, separa al héroe de la ronda de corifeos que "...evoluciona, medita, ora, suplica, sufre o se alegra” (Chancerel, 1940/1963, p.11) al narrar (y danzar)

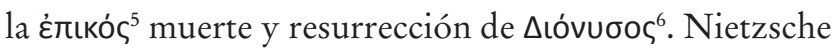
manifiesta en "El origen de la tragedia" (1871-2/2011), que no existe otro relato representado más que este. De allí que se tome que existe en toda la historia de la humanidad una sola fabula (definido por Aristóteles como lo que se cuenta): si el héroe sucumbirá a su destino -estrictamente la tragedia- o se sobrepondrá a él -por tanto, la $\kappa \omega \mu \omega \delta \delta \alpha^{7}$

Una vez que se distingue de los corifeos, el héroe les planta cara entonando su "antistrofa", el "diálogo" (Pignarre, 1959/1993, p.13) daba sus primeros pasos junto al protagonista que comenzaba a surgir, de ahora en más como una figura humana, de carne y hueso. El corro se abre dando espacio al anfiteatro para que el $\delta \rho \tilde{\alpha} \mu \alpha^{8}$ se desarrolle sin obstáculos y mane la obra.

Por tanto: “...Es, pues, la tragedia imitación de una acción esforzada y completa, de cierta amplitud, en len-

* ciscocaba@hotmail.com 
guaje sazonado, ( ) actuando los personajes y no mediante relato, y que mediante compasión y temor lleva a cabo la purgación de tales afecciones "(Aristóteles, 1974, p.145).

Entonces la tragedia es una puesta en escena de una fábula, es decir ya no dice lo que hacen los personajes, sino que se muestra con acciones, cuyo fin es tramitar un afecto que de otra manera sería imposible. Vulgarmente

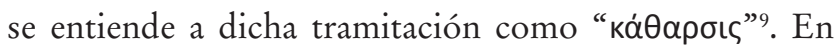
otras palabras, el drama -en tanto opuesto a la épica, la poesía, la oda, en definitiva: la acción-, ofrece un método catártico a que permite la abreacción de un afecto, un recuerdo, que no podría ser tramitado de otra manera (Breuer y Freud, 1983-95/1976, p.34).

\section{CORTE A: INT. INGLATERRA - TEATRO s. XVIII - NOCHE}

Sonido: Cascos de caballos, rumores de persona, opera.

Dicho sea de paso, cuando Hume se interroga sobre el deleite de la apreciación de una tragedia, señala lo siguiente: "Es cierto que, si aquel mismo objeto que causa dolor, que place en la tragedia, fuera puesto ante nosotros en la realidad, nos provocaría la angustia más auténtica.” (1757/2003, p.31).

Podemos decir entonces que la apreciación visual de la tragedia estaría ayudando, a quien la observa, a tramitar de manera morigerada algún tipo de afecto penoso íntimamente relacionado con la angustia.

\section{SOBRE IMPRESION PAULATINA:}

\section{CORTE A: INT. CONSULTORIO VIENES S.XX - DIA.}

Sonido de Cascos de caballos sobre adoquines, claxon, motores antiguos

Quizá Freud haya tenido en cuenta esto a la hora de plantear su "Die Traumdeutung”. La desfiguración de la acción y la imagen para tramitar lo irrepresentable (Freud, 1900/2001)

\section{SOBRE IMPRESION PAULATINA:}

\section{CORTE A: EXT. CHICAGO - PATIO DE ESCUELA}

1970 - DIA.

Sonido de Niños jugando, canciones de ronda, timbre de escuela.

Bettelheim hizo uso de esto, y fue un poco más allá:

"Todo cuento de hadas es un espejo mágico que refleja algunos aspectos de nuestro mundo interno y de las etapas necesarias para pasar de la inmadurez a la madurez total. Para aquellos que se sienten implicados en lo que el cuento de hadas nos transmite, éste puede parecer un estanque tranquilo y profundo que a simple vista refleja tan sólo nuestra propia imagen, pero detrás de ella podemos descubrir las tensiones internas de nuestro espíritu, es decir, sus aspectos más ocultos y el modo en que logramos la paz con nosotros mismos y con el mundo externo, que es la recompensa que recibimos por todas nuestras luchas y esfuerzos." (Bettelheim, 1975, págs. 354-5)

planteando de esta manera que los cuentos de hadas -se puede agregar, todo relato- ofrecen un método de tramitación y aprendizaje de las propias zonas oscuras de los sujetos a través de la identificación con el protagonista. O sea, los relatos ofrecen al sujeto algo de su propio Real de manera velada que simultáneamente lo confronta y lo apacigua.

\section{SOBRE IMPRESION:}

$2 \mathrm{~b}$ - EXT - RUINAS ATENAS - DIA.

Sepia. Formato: 16:9

Para Nietzsche la tragedia y la ciencia son coetáneas, y se las puede definir " como una unidad de contrarios, como dos fuerzas que buscan negarse una a la otra” (Carrasco Pirard, 2010, p.59). Se oponen en tanto ofrecen dos formas de tratar lo Real que son por entero contrarias.

Nietzsche distingue por un lado a la tragedia como un saber dionisíaco, un saber que en términos psicoanalíticos no pasa por el lenguaje, por lo simbólico. Que de alguna manera apaciguaría al sujeto al reconocerse impotente a las fuerzas del destino -de lo imposible de simbolizar-, permitiéndole otro tipo de existencia. Es decir, a través de la aceptación del propio dolor de vivir, de existir, el sujeto permanecerá enlazado a la vida.

Por el otro, señala a la ciencia -en tanto surge de la filosofía- un saber a través de la pura racionalidad, una salvación a través del conocimiento. Que además presupone un cierto orden universal pasible de ser descubierto a través de la razón, cuyo correlato actual seria la ciencia positiva.

Y, aun así, siendo opuestas no es conveniente que estén una sin la otra. Lo apolíneo sin lo dionisiaco devendría una ensoñación, un adormecimiento a través de dispositivos tecnológicos que de manera ficticia resuelven la vida. Y lo dionisíaco sin lo apolíneo es la destrucción de la individualidad. ${ }^{10}$

Qué mejor manera de ilustrar esto sino es a través de una comedia. En A Midsummer Night's Dream (Shakespeare, 1595/1999; Hoffman, 1999) ${ }^{11}$ se muestra a través de dos parejas, en dos planos diferentes -el mundo de los humanos y el mundo de las hadas- como pueden afectar el accionar de los vivientes cuando lo apolíneo y lo dionisiaco no marchan juntos. Así tenemos por un lado alineados a Oberón -rey de las hadas-e Hipólita -reina 
de las amazonas- como representantes de lo apolíneo; por el otro, Titania -reina de la hadas- y Teseo-duque de Atenas. En medio del conflicto, los enamorados, los artistas, y un pícaro sátiro, Puck. ${ }^{12}$ Afortunadamente, todos terminan felices y comiendo perdices. ${ }^{13}$

Sin mucho riesgo se puede hacer extensible el espíritu dionisíaco a todas las expresiones del arte. A modo de ejercicio, basta mencionar cualquier producción donde no alcancen las palabras para expresar lo que la obra transmite en lo Real, esa transmisión es completamente singular. Mencionaremos dos conocidas obras, entre otras tantas, que pueden cumplir con esto: el "Guernica" (1937) de Picasso, y Perfect day del disco "Transformer" (1972) de Lou Reed ${ }^{14}$.

FUNDE A NEGRO

\section{3 - OSCURIDAD.}

Sobre impresión: POR UNA CABEZA...

Luego: California 1870's

Sonido de cascos de caballos sobre arena, trompetas que anuncian carrera en hipódromo, sonidos de obturador de camera y de flash de magnesio en secuencia.

\section{ABRE NEGRO:}

4 - EXT - Hipódromo. - DIA.

Sepia, con colores pasteles. Formato: 1,37:1

Nada fue igual después de que se impuso el espíritu apolíneo a través revolución industrial, los adelantos técnicos modificaron para siempre la forma de vivir y pensar. Los siervos de la gleba y los esclavos no existen más, surge el obrero, el proletario, que engrosan las grandes urbes. Se solidifica la sociedad burguesa. Además, las formas de representación asimismo cambiaron.

A saber, ya no era necesario posar varias horas delante de un maestro pintor para obtener un retrato fiel. Con una fotografía bastaba. Por una módica suma, se podrían hacer todas las fotos que uno deseara, en cualquier lugar y en cualquier momento. En definitiva, comenzó a prescindirse cada vez más de la maestría del artista, y "los fabricantes confirman a la clientela que fotografiar no requiere pericia ni habilidad, que la máquina es omnisapiente y responde a la más ligera presión de la voluntad" (Sontag, 1977/2005, p.30).

Este dispositivo influenció fuertemente el arte pictórico. Gracias a las distorsiones ópticas ${ }^{15}$ de los lentes -compuestos- fotográficos la perspectiva no fue igual. Por lo fidedigno de la representación no sólo surgieron otras nuevas formas de representar el mundo, en palabras de Bazin " La fotografía, poniendo el punto final al barroco, ha librado a las artes plásticas de su obsesión por la semejanza “(1958-63/1999, p. 26), sino que las escuelas pictóricas comenzaron a declinar para dar paso a movimientos pictóricos, muchas de las cuales tienen un único representante. A fin de cuentas, Dionisio continúa apareciendo desde otros lugares.

Sin embargo, además afectar a la pintura, la fotografía permitió el surgimiento de la cinematografía. Por dos razones, la primera, la más sencillamente, la cámara cinematográfica básicamente obedece a los mismos principios físicos, químicos y mecánicos ${ }^{16}$. La segunda, un poco más elaborada, rozando el mito, habla de una apuesta de caballeros, sobre caballos (Sadoul, 1949-67/1984).

La leyenda cuenta que en 1873 Leland Standford, ex gobernador de California, dueño de caballos de carrera, expresa que, en cierto instante del galope, imperceptible para el ojo humano, las patas del caballo no tocan el piso. James Keene, presidente de la bolsa de valores de San Francisco, se inclina por la posición opuesta. Surge de este modo una apuesta. Sin embargo, hasta ese momento no había forma de corroborarlo.

Entonces, contratan al fotógrafo británico Eadweard Muybridge para que resolviera este acertijo. El primer intento es fallido, el tiempo de exposición es demasiado largo para poder detener el movimiento, sumado a que la velocidad de los obturadores de la época era también lenta. Muybridge, malogrado, se retira a investigar sobre nuevos soportes fotosensibles y a modificar el mecanismo de las cámaras.

Un par de años más tarde Muybridge repite la experiencia. Dispone 12 cámaras a lo largo de una pista de 40 metros. Los obturadores estaban sincronizados a unos hilos que una vez cortados por el caballo harían la toma. El resultado no fue el deseable, pero se acercó mucho a lo que se buscaba. Si bien carente de la nitidez optima se pudo capturar el galope del caballo. Stanford había ganado la apuesta, y Apolo amplió su dominio. ${ }^{17}$

\section{SOBRE IMPRESION PAULATINA:} CORTE A: INT. FERIA DE ATRACCIONES 1900's DIA.

Sonido de mecanismos de proyección a manivela, toses. En segundo plano: Sonidos de feria, griterío de niños, campanas voces

Si bien la reproducción del movimiento ya tenía algún recorrido gracias diversos dispositivos, y más especialmente a "juguetes" tales como el zootropo, la linterna mágica, y otros; el registro cinematográfico recién daba sus primeros pasos. Aun así, Apolo y Dionisio volve- 
rían a encontrarse y a enfrentarse, para algunos el cinematógrafo era un mero adelanto de la técnica sin mayor sentido que un registro cual cámara fotográfica -digno de las ferias de atracciones -, otros supieron utilizar el dispositivo para expresar. Bazin corrobora esto:

si Lumière muy juiciosamente no quiso vender su patente a Méliés, fue porque pensaba sin duda sacar un mayor provecho al explotarlo él mismo, pero siempre considerándolo un juguete del cual el público terminaría un día u otro por cansarse. (1958-63/1999, p. 38)

INSERT: Imagen Kinetoscopio de Edison.

INSERT: Fotos comenzando a girar según mecanismo del kinetoscopio.

INSERT: Film Edison, con presencia de flickeo.

Como la primavera, Dionisio siempre florece donde menos se lo espera. Incluso surge entre los intersticios de los estériles dispositivos tecnológicos. Sin pensarlo Dionisio se cuela incipientemente en la dificultad tecnológica de la reproducción del movimiento que tanto desveló a Edison.

INSERT: Imagen proyector. Lumière.

INSERT: obturador circular de proyector.

INSERT: Films Lumière.

y que sólo los hermanos Lumière pudieron resolver al incorporar el obturador al proyector.

Queda la pregunta: ¿de qué manera se puede verificar el surgimiento del espíritu dionisíaco en un preciso dispositivo apolíneo? La respuesta no se hace esperar demasiado: está velada en la propia definición técnica de los 24 cuadros $^{18}$ por segundo. Stricto sensu la ilusión de movimiento cinematográfica, gracias a la persistencia retiniana estudiada por Peter Mark Roget (Sadoul, 1949-67/1984, p.5), se da en 48 cuadros por segundos ${ }^{19}$. En otras palabras, para que la ilusión aparezca es necesario un cuadro negro entre fotograma y fotograma cuyo registro se obvia ya que esta presentificado mecánicamente por el obturador.

Fácilmente a través de este señalamiento, podemos continuar en los razonamientos filosóficos, reabsorbiendo este desliz dionisiaco en el pensamiento apolíneo, a través de la "alegoría de la caverna" de Platón (1988). Sin embargo, tomando cierto riesgo, se puede inferir que la continuidad de esos 24 cuadros por segundo actúa tal como el significante del Otro barrado $[\mathrm{S}(\mathbb{\nabla})]$. De otra manera, la cadencia de imágenes fijas que son proyectadas contra una pantalla oculta casi por completo la oscuridad, el vacío en definitiva: lo "no reconocido", el Unerkannte Freudiano (Schejtman, 2014).
Se evidencia como el propio dispositivo cinematográfico en simultáneo busca el adormecimiento, el alivio, por un lado, y por el otro, el despertar de los "sentidos" en el vacío. Quizás este sea el motivo por el cual la experiencia estética de "ir al cine" continúa siendo tan vigente.

INSERT: Estudio con luz natural, foros, forillos, vestuarios, etc.

INSERT: Film Méliés.

Aun así, gracias a la inventiva de Méliés ${ }^{20}$ es que Dionisio pudo apropiarse de este dispositivo adormecedor. A las imágenes en movimiento se le agregaron narraciones, al principio solo eran pantomimas mudas. Y luego, gracias a que Apolo no quiso abandonar su juguete, se fue incorporando el sonido ${ }^{21}$, y otros enceres, que complejizaron la realización cinematográfica llegando hasta lo inimaginable.

La contienda continuó hasta que los beligerantes hermanos lograron cierta paz gracias al "Manifiesto de las siete artes” (1911/2020) donde el teórico del cine, el italiano, Ricciotto Canudo define " este arte de síntesis total que es el Cine, este prodigioso recién nacido de la Máquina y del Sentimiento “. Síntesis que además se puede pensar desde el ritmo y el espacio:

Así como las formas en el Espacio son fundamentalmente Arquitectura, los ritmos en el Tiempo, ¿no son sobre todo Música? Finalmente, el «círculo en movimiento» de la estética se cierra hoy triunfalmente en esta fusión total de las artes que se llama "Cinematógrafo". Si tomamos a la elipsis como imagen perfecta de la vida, o sea, del movimiento - del movimiento de nuestra esfera achatada por los polos -, y la proyectamos sobre el plano horizontal del papel, el arte, todo el arte, aparece claramente ante nosotros. $(1911 / 2020)^{22}$

Canudo piensa que en el arte cinematográfico se conjugan en simultáneo la arquitectura, la escultura, la pintura, la música, la danza y la poesía/literatura.

FUNDE A NEGRO

\section{5 - OSCURIDAD.}

Sobre impresión: ARE YOU EXPERENCIED? ${ }^{23} \ldots$ Luego: Viena, 1900's

Sonido de reloj de iglesia, cascos de caballos, ensayos de orquesta, mezclado con Hendrix

\section{ABRE NEGRO:}

6 a - EXT - Berggasse 19-DIA.

Colores pasteles. Formato: 1,66:1

El recorrido presentado hasta el momento, a la manera de una genealogía imperfecta, ha buscado señalar el constante conflicto entre dos soluciones posibles ante la 
impotencia frente a lo Real que le es intrínseco a todo ser humano. Por un lado, la ciencia, representada por Apolo, que promete una solución adormecedora al plantear todas las soluciones a través de la razón. Por el otro, el arte, donde Dionisio lleva su estandarte, donde las soluciones van de la mano a la aceptación de lo trágico, en tanto angustia inevitable ante la incertidumbre. ${ }^{24}$

Ante esta contienda, el cine, esa síntesis entre dispositivo técnico y sentimiento, debió aguardar al preciso momento para eclosionar luego de años de estar preparado. Así también, el psicoanálisis tuvo que esperar el preciso momento para poder ver la luz de la mano de Freud.

$\mathrm{Al}$ igual que el origen del cine, en tanto dispositivo y espectáculo, confluyen en dos inventores "fundamentales", el psicoanálisis confluyó en Freud como el "fundador de su discursividad". Foucault lo explica de la siguiente manera: "Estos autores tienen la particularidad de que no son solamente autores de sus obras, de sus libros. Han producido algo más: la posibilidad y la regla de formación de otros textos "(1969/2000-5, p. 24)

Haciendo un salto inferencial, no sólo se puede manifestar que el psicoanálisis es también una síntesis de la disputa entre ciencia y Arte, dado que su origen es netamente científico, pero aun así se dirige a un lugar que no logra de terminar de asirse -la oscuridad del inconsciente-. Sino que también se puede afirmar, sin mucho peligro, que tanto cine y psicoanálisis al ser hijos de su época, la misma época, comparten puntos discursivos, transversales según Foucault, a los cuales se pueden atender.

6 b - INT - Consultorio, 20 Maresfield Gardens, London NW3- DIA.

Colores saturados. Formato: 1,66:1

Es en esta tónica que Rancière señala:

... si la teoría psicoanalítica del inconsciente es formulable es porque, fuera del terreno propiamente clínico, ya existe cierta identificación de un modo inconsciente del pensamiento, y el campo de las obras de arte y de la literatura se define como el ámbito de efectividad privilegiada de este 'inconsciente' (2001/2006, pp. 21-22)

Afirmación que se asemeja a la que profiere Lacan en su seminario 11 cuando señala la existencia de un modo natural de la transferencia y que el psicoanálisis lo único que hizo fue descubrirlo y ponerlo a trabajar (Lacan, 1964/1987, p.131).

De esta manera Rancière no confunde en ningún momento este inconsciente presente en el campo de las artes, con el psicoanalítico, así como Freud (2001/2006) no confunde lo visible representado con lo visual. Por el contrario, privilegia la lectura que hace Freud en los detalles de ciertas obras donde este genio es capaz de percibir algo que muchas veces escapa al público convencional -la verdad de la historia del sujeto, un síntoma o un fantasma. Detalles que los analistas continúan percibiendo hoy en día.

Es en estos detalles que Freud percibe al espíritu Dionisíaco, en la experiencia estética de cada sujeto.

FUNDE A NEGRO

\section{7 - OSCURIDAD.}

Sobre impresión: O FORTUNA...

...VELUT LUNA...

...STATU VARIBILIS... ${ }^{26}$

Luego: En la actualidad.

Sonido de vacío. Luego paulatinamente "What your soul sings" 27

\section{ABRE NEGRO}

8 a - INT - Foro vacío - DIA.

Utilería: Un diván.

Colores saturados. Formato: 16:9

Iluminación teatral, luces cálidas.

Hasta aquí hemos planteado que arte y psicoanálisis se asemejan en tanto que ambos apuntan hacia ese lugar donde se presenta lo inefable. Y lo hacen a través de la experiencia,

El psicoanálisis propone la experiencia analítica que se alinea con el concepto que Foucault denomina como "parresía". Literalmente significa "decirlo todo", pero,

La parresía esencialmente no es ni la franqueza ni la libertad de expresión, sino más bien la técnica que permite al maestro utilizar como es debido todo aquello que es eficaz para el trabajo de transformación de su discípulo. La parresía es una técnica que se utiliza en la relación entre el médico y el enfermo, entre el maestro y el discípulo; es esa libertad de movimiento que hace que en el campo de los conocimientos verdaderos se pueda utilizar aquello que es pertinente para la transformación y mejora del sujeto. (Freud, 1981-2/2010, p.79)

En pocas palabras, el psicoanálisis, al aplicar la asociación libre -y su consecuente interpretación-, pone a trabajar el buen decir oponiéndose de esta manera a la "palabra vacía", a la retórica, en pos de ese punto inefable de la verdad del sujeto, de su Real. Más sencillamente, a través de la indicación "del decirlo" todo, y a sabiendas de que no se puede decir todo, se circunda, se aproxima, a ese "no todo".

\section{8 b - INT - Foro vacío - DIA.}

Utilería: Una cámara cinematográfica.

Colores saturados. Formato: 16:9

Iluminación teatral, luces cálidas. 
Ahora bien, para poder explicar la experiencia estética deberemos recurrir a esa parte de la filosofía que a partir de Kant se ocupa de lo sublime. Deleuze explica en su seminario "Kant y el tiempo" que "Lo sublime ocurre cuando la imaginación es puesta en presencia de su propio límite. Está espantada, la ambigüedad entre el ritmo y el caos es enorme" (1978/2008, p.89). Con esto está señalando que de alguna manera lo sublime escapa de cualquier forma de razonamiento, incluso escapa aquello a lo que nuestra imaginación puede devolvernos, "lo que no puede ser imaginado “(1978/2008, p.89). Esta parte de la filosofía se dio a conocer como Estética.

Yendo más allá, Gadamer (1992/2001) recoge el guante y partiendo de que el arte, en tanto sublime, se impone inexorablemente -cualquiera sea su manifestación-, se interrogara por la forma en que el arte "enuncia la verdad". Teniendo en cuenta que es imposible decirlo todo, este discípulo de Heidegger, recurre a lo óntico, al ser del arte.

Las obras de arte tienen un rango óntico elevado, y esto se muestra en la obra de arte tenemos la experiencia de que el arte es algo que sale fuera; y a eso es lo que denominamos la verdad. (Gadamer, 2001, p.236)

El arte, o mejor dicho las obras de arte, no tienen objeto, finalidad, en definitiva, no tiene función alguna; son. Por el contrario, "existe para ser contemplado" (Gadamer, 2001, p.231), y es en esta acción que surge algo de una verdad que es distinta a la que se puede acceder a través de la razón. Es por este motivo que Gadamer define a la experiencia estética, a la contemplación, en tanto "absoluta" ya que estaría desligada, sería independiente de toda condición histórico y social, así como podría serlo la religión y la filosofía. O sea, una obra de arte, tal como lo hace la filosofía, nos hará dialogar con otras obras de artes anteriores, y nos instará a dialogar con las obras futuras. Cabe aclarar que, para Gadamer, lo opuesto a lo absoluto es lo relativo.

Ahora bien, para la verdad que emerge a través de la experiencia estética Gadamer le reserva el título de $\alpha \lambda n^{\theta} \theta \varepsilon \alpha^{28}$ en tanto desvela, hace evidente. Y que también la piensa como esa energía pura en términos aristotélicos, en tanto movimiento sin camino, sin meta. Sin embargo, este concepto se opone a la Veritatis, a la doxa, en tanto estas cuentan como opinión fundamentada en algún saber previo. Nuevamente aquí se observa el conflicto entre lo apolíneo y lo dionisíaco.

Teniendo en cuenta la aletheia, Gadamer nos da una nueva definición de contemplación en tanto experiencia estética: “...Contemplar (...) no es ser mero espectador. Significa 'estar por completo en ello', es decir, una suprema actividad y realidad” (2001, p.243).

Quizás, como una primera conclusión posible, podemos señalar que tanto experiencia analítica, como experiencia estética, además de ser singulares para cada suje$t^{29}$, se dirigen a señalar aquello que no puede ser dicho, apelan a esa verdad que no puede ser puesta en palabras. En definitiva, apuntan al real.

\section{CORTE A NEGRO}

\section{9 - OSCURIDAD.}

Sobre impresión:

Las obras de arte surgen del esfuerzo por expresar ideales éticos. Determinan la imaginación y la sensibilidad del artista...

Su obra siempre será el resultado de un esfuerzo intelectual en busca del perfeccionamiento del hombre, la expresión de una visión del mundo que nos atrapa por la armonía del pensar y del sentir, por su dignidad y sencillez. Andrei Tarkovski.

(Esculpir en el tiempo., 1984/1999, pág. 48)

CORTE A NEGRO

10 - OSCURIDAD.

Sobre impresión: Continuará... CORTE A NEGRO

11 - Roll up créditos. Bibliografía

12 - Pos títulos

\section{Referencias}

Aristóteles. (1974). Poética de Aristóteles. Edición trilingüe por García Yerba, V. Editorial Gredos.

Bazin, A. (1958-63/1999). ¿Qué es el cine? Ediciones Rialp.

Bettelheim, B. (1975). The uses of enchantment. The meaning and importance of fairy tales. Int.: EPUB GRATIS. Org.

Breuer, J., y Freud, S. (1893-95/1976). Estudios sobre la histeria. En S. Freud, Obras completas. Vol. II. Amorrortu Editores.

Canudo, R. (1911/2020). Manifiesto de las siete artes. Obtenido de Proyecto IDIS: https://proyectoidis.org/manifiesto-de-las-siete-artes/ 
Carrasco Pirard, E. (2010). El hombre y lo otro. Ensayos sobre Nietzche, Heidegger y Sartre. Editorial Universitaria.

Chancerel, L. (1940/1963). El teatro y los comediantes. Breve historia del arte y los artistas. EUDEBA.

Coen, E., \& Coen, J. (Dirección). (2016). Hail, Caesar! [Película].

Deleuze, G. (1978/2008). Kant y el tiempo. Equipo Editorial Cactus.

Deleuze, G. (1983/1994). La imágen-movimiento. Estudios sobre cine 1. Paidós Comunicación.

Foucault, M. (1969/2000-5). ¿Qué es un autor? Obtenido de http://23118.psi.uba.ar/academica/carrerasdegrado/musicoterapia/informacion_adicional/311_escuelas_psicologicas/docs/Foucault_Que_autor.pdf

Foucault, M. (1969/2002). Arqueología del saber. Siglo XXI Editores.

Foucault, M. (1981-2/2010). La hermenéutica del sujeto. De la Piqueta.

Freud, S. (1900/2001). Obras Completas. Tomo V. La interpretacion de los sueños. Amorrortu Editores.

Gadamer, H.-G. (2001). Palabra e imágen: “así de verdadero, así de óntico” (1992). En Antologia (págs. 135-150). Ediciones Sígueme.

Garibay K., A. M. (1964/1997). Mitología Griega. Dioses y héroes. Editorial Porrúa.

Graves, R. (1955/2007). Los mitos griegos. Vol 1. Alianza Editores.

Hazanavicius, M. (Dirección). (2011). The Artist [Película].

Hoffman, M. (Dirección). (1999). A Midsummer Night's Dream [Película].

Hume, D. (1757/2003). De la tragedia y otros ensayos sobre el gusto. Editorial Biblos.

Lacan, J. (1964/1987). El seminario. Libro 11. Cuatro conceptos fundamentales del Psicoanálisis. Paidos.

Lamet, P. M., Rodenas, J. M., \& Gallego, D. (1968). Lecciones de cine. Historia, estética y sociología. II. Ed. Mensajero del Corazón de Jesús.

Longhurst, R. S. (1957/1973). Geometrical and physical optics. 3erd Ed. Longman.

Macgowan, K., \& Melnitz, W. (1959/1987). Las edades de oro del teatro. Fondo de Cultura Económica.

Milerson, G. (1991). The technique of lighting for television and film.- 3rd. ed. Focal Press.

Motta, C. G. (2013). Las películas que Lacan vio y aplicó al psicoanálisis. Editorial Paidós.

Nitetzsche, F. (1871-2/2011). El nacimiento de la tragedia y escritos preparatorios. En Obras Completas. Vol. I. Escritos de juventud (págs. 329-477). Editorial Tecnos.

Pignarre, R. (1959/1993). Historia del teatro. EUDEBA.

Platón. (1988). Diálgos IV: La república. Editorial Gredos.

Rancière, J. (2001/2006). El inconsciente estético. Del estante editorial.

Sadoul, G. (1949-67/1984). Historia del cine mundial. Desde los origenes hasta nuestros dias. 8va edicion. Siglo veintiuno editores.

Safinia, F. (Dirección). (2019). The Professor and the Madman [Película].

Samuelson, D. W. (1986). Motion picture camera and lighting equipment. 2nd. ed. Focal Press.

Schejtman, F. (2014). ¿Qué es un agujero? En J.-A. Miller, Estudios sobre el autismo. (págs. 73-92). Coleccion Diva.

Scorsese, M. (Dirección). (2011). Hugo [Película].

Sears, F. W. (1963). Fundamentos de Fisica III. Optica. Aguilar.

Shakespeare, W. (1595/1999). A Midsummer Night's Dream. En The complete works (págs. 153-173). Gramercy.

Sontag, S. (1977/2005). Sobre la fotografía. Alfaguara.

Tarkovski, A. (1984/1999). Esculpir en el tiempo. Ediciones Rialp, S.A.

Wachowski, L., \& Wachowski, L. (Dirección). (1999). The Matrix [Película].

Weir, P. (Dirección). (1989). Dead Poets Society [Película].

1 Thespis. Según Aristóteles, el primer dramaturgo.

2 Pisístrato.

3 Tragedia: gr. tragōidía. Palabra compuesta de tpáyos “carnero” y y ửń “canción”. 
4 Ditirambo: gr. dithýrambos. "composición poética en honor de Dioniso".

5 Épica: de ěroc, épos “palabra, historia, poema”

6 Dionisio: Dionysos. [ver (Graves, 1955/2007, págs. 98-106) (Garibay K., 1964/1997, págs. 22-24)].

7 Comedia: kōmōidía. Relato dramático con final feliz, es decir, el protagonista tuerce su destino.

8 Drama: gr. drâma. De dran, acción.

9 Catarsis: gr. kátharsis "purga", "purificación".

10 Ver (Nitetzsche, 1871-2/2011, págs. 329-477) y (Carrasco Pirard, 2010, págs. 51-77)

11 Existen varias otras versiones fílmicas.

12 El protagonista de "Dead Poets Society" (Weir, 1989) no sólo interpreta a Puck en una escena, sino que en su "vida personal" también se encuentra tironeado entre lo "apolíneo y lo dionisíaco”. Quizá sea esta una buena clave de lectura para este film.

13 Augusto Fernández (1937-2018) señalaba algunas veces que el conflicto subyacente de esta obra era entre "Eros y Thanatos", y en otros momentos entre "Marte y Dionisio". Al fin de cuentas, se lo puede entender también entre pulsión de vida y pulsión de muerte.

14 Para comprender este concepto es imprescindible poder apreciar al “Guernica” original (Museo Reina Sofia, Madrid), y escuchar "Perfect Day" en la intensidad sonora adecuada.

15 "La distorsión es una aberración que no procede de la falta de nitidez de la imagen, sino de una variación del aumento con la distancia al eje." (Sears, 1963) O sea, la deformación en “almohada” o en "barril” (Longhurst, 1957/1973, pág. 387) que se produce al utilizar, por ejemplo, lentes gran angular, o mejor aún, ojo de pez, que curvan el horizonte y es generalmente observable en los bordes del cuadro, no así en su eje.

16 Por cuestiones de espacio no se entrarán en muchos detalles con esto.

17 Ver (Lamet, Rodenas, \& Gallego, 1968) (Sadoul, 1949-67/1984, págs. 1-15)

18 No ahondaremos aquí en la diversidad de cuadros que propone la mecánica cinematográfica, ni le video. Solo resta señalar que en los inicios bastaban con 16 cuadros por segundo para que se produjese la ilusión de movimiento.

19 Por cuestiones de espacio y tiempo no entraremos aquí en las hermosas disquisiciones que aporta Deleuze en "La imagen-movimiento" (1983/1994)

20 Recomendamos aquí el film "Hugo" (Scorsese, 2011), donde se observa como aun la maquina transmite algo que no le es propio.

21 Aquí sugerimos el film “The Artist” (Hazanavicius, 2011) para pensar el pasaje del cine mudo al sonoro.

22 Es interesante cómo se despliega esto en el film "Hail, Caeser!” (Coen \& Coen, 2016)

23 En: “Are you experienced?” 1967. The Jimi Hendrix Experience.

24 Recordemos la escena en “The Matrix” (Wachowski \& Wachowski, 1999), cuando Morfeo -casualmente, el dios de los sueñosle ofrece la alternativa de despertar a lo Real, sin asistencia mecánica alguna, o continuar durmiendo en el placentero sueño de las maquinas.

25 Es interesante en este aspecto el film “The Professor and the Madman” (Safinia, 2019) donde se escenifica la creación en conjunto de una obra monumental, el Diccionario de Oxford.

26 En Carmina Burana 1935-6. Orff, Carl.

27 En 100th Window, 2003. Massive attack.

28 Aletheia: literalmente "la verdad"

29 No fue por omisión que no hayamos desarrollado más la singularidad de la experiencia, ya sea estética o analítica, sino que fue para no desviarnos del hilo conductor. 